\title{
Efektifitas Pemakaian Solvent Sebagai Pelarut Formula Insektisida Dalam Membasmi Nyamuk Aedes Aegypti Guna Mencegah Penyakit Demam Berdarah Dengue
}

\author{
Edy Supriyo*, Fransisca Sri Nugraheni dan R.T.D. Wisnu Broto \\ Program Studi Teknik Kimia, Departemen Teknologi Industri, Sekolah Vokasi, Universitas Diponegoro \\ Jl. Prof. Soedarto, Tembalang, Semarang, Jawa Tengah 50275, Indonesia \\ Email: edyspy2000@yahoo.co.id
}

\begin{abstract}
Abstrak
Formula yang ada dipasar bebas hanya dapat membunuh nyamuk saja, maka dalam penelitian ini akan dilakukan Produksi formulasi insektisida sebagai insektisida alternative pembunuh nyamuk dan jentik, dimana agrisol dan dodecyl benzen sulfonat merupakan emulsifier nonionic dan anionic sert bersifat hydrophilic. Penelitian ini bertujuan untuk menentukan konsentrasi emusifier yang tepat dalam proses formulasi insektisida, sehingga kestabilan emulsi antara minyak dengan air dalam waktu yang cukup lama Pada percobaan pembuatan emulsifier konsentrat kemudian dilakukan uji kestabilan emulsi antara minyak dan air serta uji effikasi Maka dapat diproduksi formula yang digunakan sebagai bahan dasar insektisida dalam membasmi nyamuk dan jentik nyamuk Aedes aigepty. Disamping itu juga dapat menjadi formula obat nyamuk (insektisida) alternatif yang mudah diaplikasikan oleh masyarakat. Hasil penelitian menunjukan bahwa emulsifier concentrat yang terbaik adalah pada percobaan dengan formula komposisi: 17,38\% propoxure; Malathion 17,39\% agrisol; 13,01\% DBS, 47,83\% Xyline dan 4,35\% additive dalam \% berat. Dengan total emulsifier yang digunakan 30,5\% w/w equivalent dengan 30 EC Dari uji kestabilan antara minyak dan air didapat pelarut yang terbaik adalah thiner, dengan membentuk micro emulsi pada lapisan air sampai 12 minggu lebih, kestabilan emulsi tercapai pada CMC 0,42\% v/v pada lapisan minyak. Dari uji effikasi dengan pengencer thiner sebanyak 10x setelah dianalisa profitabilitas sesuai $L_{D} 50$, didapat dosis . 0,025 -0,25\% ( V/V), baik untuk telur nyamuk maupun jentik Aedes aegypti dengan prosentasi kemation 45-90\%
\end{abstract}

Kata kunci : formulation; demam berdarah; insektisida

\section{Abstract \\ Effectiveness of Solvent Usage as a Solvent for Insecticide Formula in Eradicating Aedes Aegypti Mosquitoes to Prevent Dengue Hemorrhagic Fever}

Pesticide formulation which are available in market are only killed the mosquitos but not the larvae. Therefore Production formulation of insecticide as inscticide alternative to eridicate mosquitos and its larvae with agrisol and dodecyl benzen sulfonat as emulsifier nonionic and anionic hydrophilic. The reseach work was aimed to determine the best emulcifier concentrate in pesticide formulation so that the emulsion of oil and water will be stable for a long time. In reseach work the emulsifier concentrate was made, than emulsion stability test between oil and water as well as its effectivity were condected. This formulation could be used as active engridient for insecticide to kill Aedes aigepty mosquitos and its larvae and could be applied in the community. The research showed that formulation consist of komposisi: 17,38\% propoxure; Malathion 17,39\% agrisol; 13,01\% DBS, 47,83 \% Xyline dan 4,35\% additive dalam \% berat. Dengan total emulsifier yang digunakan $30,5 \% \mathrm{w} / \mathrm{w}$ equivalent $30 \% \mathrm{w} / \mathrm{w}$. Stability test of oil and water showed that the best solvent is 
thiner, and formed micro emulsi on water film for more than 12 week. Emulsion was stable by CMC 0,42\% v/v on oil film. From effication test and than analysis profitability revealed that $L D_{50}$, was . 0,025 $-0,25 \%(\mathrm{~V} / \mathrm{v})$, both for larvae and mosquitos presented dead 45-90\%.

Keywords : Formulation; dengue fever; incestiside

\section{PENDAHULUAN}

Penyakit demam berdarah dengue pertama kali terjadi di Indonesia, adalah Surabaya dan Jakarta, Kemudian pada tahun 1973 dengan jumlah kematian 24 orang, beberapa tahun selanjutnya menyebar ke beberapa propinsi di Indonesia. Dengan jumlah kasus terus meningkat, pada Tahun 1996, sebanyak 45.548 kasus kengan kematian 1.234 orang, Tahun 1998, sebanyak 72.133 orang. dan Tahun 2004 sebanyak 26.015 dengan kematian 384 orang untk DKI (Candra, 2010 ).

Banyak insektisida beredar di pasar tetapi belum efektif membunuh nyamuk secara keseluruhan. Misalnya: Abate, hanya dapat membunuh jentik-jentik nyamuk dalam skala kecil. Obat nyamuk komersial seperti Baigon, Kingkong, Marfu, Vape membunuh nyamuk, Mathion dan Fenthion. Insektisida yang digunakan pada saat foging biasanya emulsinya yang terjadi di air bersifat destabil walaupun dengan konsentrasi tinggi juga belum dapat sempurna karena hanya membunuh nyamuk dewasa. Oleh karena itu diperlukan suatu usaha untuk mendapatkan suatu formula insektisida alternative yang dapat membasmi nyamuk Aides aigepty sekaligus jentikjentik nyamuk yang hidup diair.

Untuk itu penelitian ini telah dilakukan untuk memproduksi formula insektisida yang dapat membunuh nyamuk sekaligus jentiknya, dengan menggunakan campuran surfactant antara Agrisol dan dodecyl benzen sulfonat yang dikenal sebagai Emulsifier nonionic dan anionic dan bersifat hidrophilic, diharapkan dapat terjadi kestabilan emulsi didalam air. Penelitian ini dilakukan untuk mengetahui konsentrasi surfactant yang tepat dalam proses formulasi insektisida, dan untuk mengetahui konsentrasi dodecyl bensen sulfonat yang dibutuhkan sebagai campuran surfactant dalam membentuk emulsi yang stabil antara minyak dengan air.

\section{METODOLOGI}

\section{Pembuatan emulsifier konsentrat}

\section{Prosedur Percobaan}

Bahan - bahan yang dibutuhkan dalam penelitian ini akan dipersiapnkan, ditimbang dan diukur sesuai dengan variable yang digunakan dalam penelitian ini, yaitu propoxure (20 gram), Agrisol (20 gram), DBS (5) dan 20 gram), Xyline (55 gram), IPA (2 gram) , PG (2 gram) dan Toluen ( 1 gram ). Tahapan yang dilakukan yaitu : a) Propoxure dan xyline dimasukkan ke dalam labu leher 3 dan dipanaskan sampai temperatur $40^{\circ} \mathrm{C}$, sambil dilakukan pengadukan hingga propoxur terlarut. b)Emulsifier ( Agrisol ), IPA dan PG dimasukkan kedalam labu leher tiga, pengadukan dilanjutkan hingga semua terlarut dan homogen, kemudian dilakukan pengulangan dengan variable konsentrasi DBS. c) Konsentrat yang terbentuk selanjutnya di emulsikan dalam air, selanjutnya dilihat dispersi yang terjadi dalam air. d) Kemudian dilakukan pengulangan dengan konsentrasi surfactan DBS yang berbeda yaitu : DBS (surfactant) : 0, 5,10,15 dan 20. e) Konsentrat yang didapat dianalisa secara fisis dan kimianya untuk dibandingkan dengan standart.

\section{Kestabilan Emulsi}

Langkah-langkah percobaan untuk kestabilan emulsi minyak dalam air adalah sebagai berikut : a) Bahan - bahan yaitu emulsifier konsentrate (1ppm), minyak tanah (50 gram), Air ( 50 gram). b) Bahan - bahan tersebut diatas kemudian dimasukan dalam erlemeyer $1000 \mathrm{cc}$, temperatur masih dalam temperatur ruang $32^{\circ} \mathrm{C}$, kemudian dilakukan pengadukan selama 30 menit. c) Kemudian emulsi yang terjadi diamati dan dicatat waktu minyak yang terpisah dan air yang terpisah sampai emulsi tidak stabil, ulangi percobaan pada konsentrasi dan minyak yang berbeda. d) Amati stabilitas emulsi yang terjadi dan catat waktu pemisahan minyak dan air dari 
emulsi yang terbentuk. d) Sehingga didapat 1 konsentrat yang terbaik dan 1 minyak yang terbaik juga. e) Akhirnya didapati emulsi stabil dalam waktu yang relatif lama. Kemudian dilakukan uji toxicitas.

\section{Uji Efikasi}

Prosedure dalam analisa effikasi dengan $\mathrm{LD}_{50}$ adalah sebagai berikut : a) Menyediakan binatang uji (nyamuk Aedes aegypti bentina strain Semarang yang berumur 3-5 sejumlah 20 ekor). b) Nyamuk tersebut diambil dari sarang nyamuk selanjutnya dan dimasukan dalam glas chamber yang dilengkapi dengan respirasi c) Formula Insektisida terlebih dulu diencer dengan solvent (10X). Selanjutnya diseprotkan dalam glass chamber dengan spryer, amati yang terjadi dalam glass chamber. d) Konsentrasi formula yang diambil yaitu 0,75\%, 0,5\%;0,25,0,125 dan 0,0625\% dengan $3 \times$ ulangan. e) Amati dan catat jumlah binatang yang mati dan sesuaikan dengan $\mathrm{LD}_{50}$,

\section{HASIL DAN PENGAMATAN Konsentrat Terbaik}

Dengan adanya campuran surfactant antara Non Ionic (octyl phenol) dan anionic ABS ini seperti terlihat pada tabel 4, kelarutan propoxure dalam xyline terlihat lebih tinggi dan larut semua pada percobaan dimana konsentasi surfactan
Agrisol yang digunakan pada $20 \mathrm{gr}$ dan $15 \mathrm{gram}$ DBS. !5 gram DBS yang digunakan yang mampu melarutkan propoxur dalam xyline dan toluen akan lebih besar, sehingga tidak terjadi pengendapan selama 12 minggu baik didalam pembuatan formulasi maupun dalam penyimpanan serta pemakaiannya. Dari Percobaan seperti terlihat pada Tabel 2 selanjutnya dianalisa secara deskriptif dan dibandingkan dengan standart yang ada dari Komisi Pestisida Indonesia secara keseluruhan dari nilai $\mathrm{BJ}, \mathrm{pH}$, viscositas dan indeks biasnya nampak bahwa percobaan 4 dan 5 mendekati nilai standar dari Komisi Pestisidas Indonesia. Tetapi pada kekentalan dan $\mathrm{pH}$ hanya percobaan 4, viskositas percobaan 5 terlalu rendah dan propoxure yang mengendap juga terlalu banyak. Dengan demikian maka percobaan 4 merupakan percobaan yang terbaik, dilihat dari semua sifat fisis dan endapan yang terbentuk merupakan formula yang memenuhi syarat.

Demikian juga dikatakan oleh Widro et al (2005) bahwa nilai perbandingan fraksi mole non ionik dan anionik untuk menghasilkan excess free energy dalam pembetukan micelle, dicapai untuk semua nilai mole fraksi nonionik surfactant. Tetapi nilai minimum untuk dodecyl $\beta$ maltosa sebagai non ionik : dodecyl trimethyl sulfonat sebagai anionok $=0.7$, sedangkan dalam penelitian ini emulsifier yang digunakan adalah campurant antara agrisol non ionik dibanding dodecyl benzen sulfonat sebagai anionik adalah 0,75.

Tabel 1. Percobaan Pembuatan konsentrat, dengan konsentrasi DBS yang berbeda

\begin{tabular}{lccccc}
\hline Komponen & Percb 1 & Percb 2 & Percb 3 & Percb 4 & Percb 5 \\
\hline Propoxure ( gr ) & 20 & 20 & 20 & 20 & 20 \\
Malation (gr) & 5 & 5 & 5 & 5 & 5 \\
Agrisol (gr ) & 20 & 20 & 20 & 20 & 20 \\
DBS (gr ) & 0 & 5 & 10 & 15 & 20 \\
Xyline (gr ) & 50 & 50 & 50 & 50 & 50 \\
IPA (gr) & 2 & 2 & 2 & 2 & 2 \\
PG (gr) & 2 & 2 & 2 & 2 & 2 \\
Toluen (gr ) & 1 & 1 & 1 & 1 & 1 \\
Jumlah & 100 & 105 & 110 & 115 & 120 \\
Sisa propoxure & 5 & 4,5 & 2 & 0,5 & 1,3 \\
\% Surfactant & 0,20 & 0,24 & 0,27 & 0,30 & 0,33 \\
\hline
\end{tabular}


Tabel 2. Analisa sifat-sifat fisik emulsifier konsentrat dari percobaan dengan berbagai konsentrasi DBS yang berbeda

\begin{tabular}{|c|c|c|c|c|c|}
\hline Komponen & Percb 1 & Percb 2 & Percb 3 & Percb 4 & Percb 5 \\
\hline BJ.Rata-rata & 0,7188 & 0,7344 & 0,6354 & 1,1510 & 1,1533 \\
\hline pH Rata-rata & 9,70 & 8,33 & 8,10 & 7,97 & 8,07 \\
\hline ViscositasRata-rata & 2,22 & 2,81 & 3,52 & 4,05 & 3,75 \\
\hline Index biasRata-rata & 1,311 & 1,326 & 1,328 & 1,348 & 1,345 \\
\hline Warna & $\begin{array}{l}\text { Kuning } \\
\text { Kemerahan }\end{array}$ & $\begin{array}{l}\text { Kuning } \\
\text { Kecokelat }\end{array}$ & $\begin{array}{l}\text { Kuning } \\
\text { bening }\end{array}$ & $\begin{array}{l}\text { Kuning } \\
\text { Bening }\end{array}$ & $\begin{array}{l}\text { Kuning } \\
\text { Bening }\end{array}$ \\
\hline $\begin{array}{l}\text { Korosifitas } \\
\text { Mudah Meledak }\end{array}$ & $\begin{array}{l}\text { Tak korosif } \\
\text { Tidak }\end{array}$ & $\begin{array}{l}\text { Tak korosif } \\
\text { Tidak }\end{array}$ & $\begin{array}{l}\text { Tak korosif } \\
\text { Tidak }\end{array}$ & $\begin{array}{l}\text { Tak korosif } \\
\text { Tidak }\end{array}$ & $\begin{array}{l}\text { Tak korosif } \\
\text { Tidak }\end{array}$ \\
\hline
\end{tabular}

\section{Uji Kestabilan Emulsi}

Fraksi air $50 \%$ dan $50 \%$ v/v fraksi minyak, dapat dilihat destabilitasnya melalui fraksi air maupun minyak tanah yang terpisah secara sempurna (Gambar 1.a ). Sedangkan pecahnya emulsi pada lapisan minyak tanah untuk emulsifier consentrat EC 1 ppm waktunya 14 jam selanjutnya untuk 2 ppm dan 3 ppm waktunya sama 24 jam. Hal ini digunakan untuk mengukur instabilitas secara fisik. Hal ini disebabkan tidak adanya daya tarik menarik antara molekul-molekul surfactan dengan air maupun minyak.

Nilai dari fraksi minyak yang terpisah pada campuran $50 \%$ v Thenir dan $50 \%$ v air terlihat pada ( Gambar 1.b ), maka fraksi minyak yang terpisah pada thiner pada EC 1 ppm 84\%, 2 ppm 64\% dan 3 ppm 46\%. Menurut (Bink et al., 2003). hasil uji stabilitas maka pada konsentrasi 3 ppm, pada lapisan minyak fraksi ( decane ) minyak yang terpisah adalah $47 \%$, $(0,47)$. Paramter-parameter yang sudah dihitung mengindikasikan bahwa dalam sistem 2 nonionic dan anionik terjadi sinergisme dalam mono layer yang stabilitas emulsi dan dalam pembentukan miccele 0,47, namun demikian konsentrasi pada permukaan yang kecil, maksimum terjadi pada interface air udara dan farksi minyak yang terpisah minimum berhubungan erat dengan CMC pada 0,47 (Bronislow et al., 2003). terjadi pada temperatur $28{ }^{\circ} \mathrm{C}$, Dalam penelitian ini fraksi minyak yang terpisah untuk 3 ppm EC pada thiner $42 \%(0,42)$.

Sedangkan pecahnya emulsi pada lapisan minyak untuk solar dengan emulsifier consentrat EC 1 ppm, 2 ppm dan 3 ppm waktunya yang dibutuhkan sama 30 jam terpisah secara sempurna (Gambar 1.c). Disini terlihat bahwa untuk minyak tanah maupun solar terjadi ketidak stabilan emulsi karena emulsi yang terjadi pecah sehingga lapisan minyak dan air dapat terpisah secara sempurna, Hal ini dimungkinkan kurangnya dosis untuk emulsifier concentrat pembuatan stabilisai emulsi antara minyak dan air, sedangkan dalam penelitian

\section{Uji Efikasi}

Pada percobaan ini thiner sebagai pelarut yang terbaik karena dapat membentuk kestabilan emulsi dalam minyak, racun dari bahan aktif pestisida golongan karbamat dan organoposfat dapat teremulsikan bersama minyak dan air, sehingga dapat membunuh nyamuk maupun jektik saat dilakukan foging. Dari uji efikasi yang dilakukan mulai dari konsentrasi 40\%, kemudian diturunkan terus sampai didapat dapat yang efektif dalam membunuh nyamuk seperti terlihat pada tabel 3. menunjuk konsentrasi yang terbaik jika diambil $L D{ }_{90}$ adalah 0,25\% (v/v), dengan berat bahan aktif perstisida yang teremulsikan sebanyak 0,00625 gr. Sedang jika dipakai uji efikasi dengan $L D_{50}$, terhadap hewan uji ( nyamuk dan ,jentik-jentik ) setelah dilakukan dengan pengenceran 10 kali. Dari tabel 3 didapat bahwa uji $L_{D} 50$ dosis yang terbaik untuk foging adalah $0,125 \mathrm{gr}$ dengan bahan aktif yang teremulsikan dalam minyak terhadap air saat dilakukan foging sebesar 0,00325 gr beberapa hewan uji, sedangkan standart bahan aktif yang terbawa dari WHO 0,7 gr, sehingga lebih kecil dari standart dan 
amam bagi lingkungan. Kelebihan ini digunakan sebagai angka keamanan. Diharapkan formula tersebut diatas jika digunakan untuk foging dapat digunakan dosis 0,125 - 0,25 \% (v/v0 sedangkan pelarut yang terbaik thiner menurut dengan surfactan agrisol dan dodecyl benzen sulfonat.

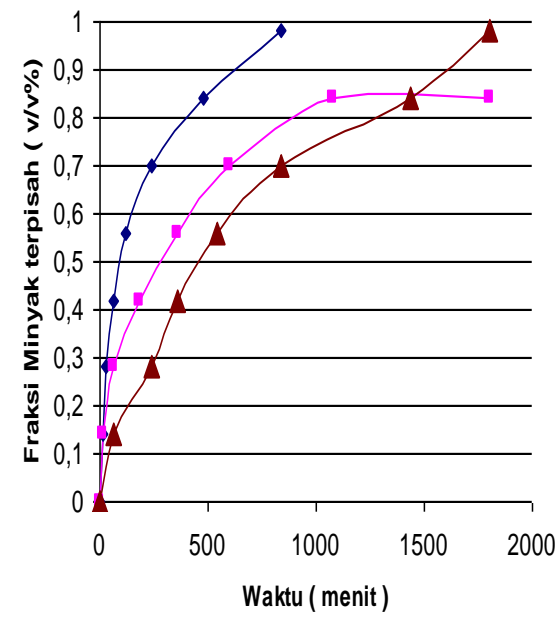

(a) 1 ppm

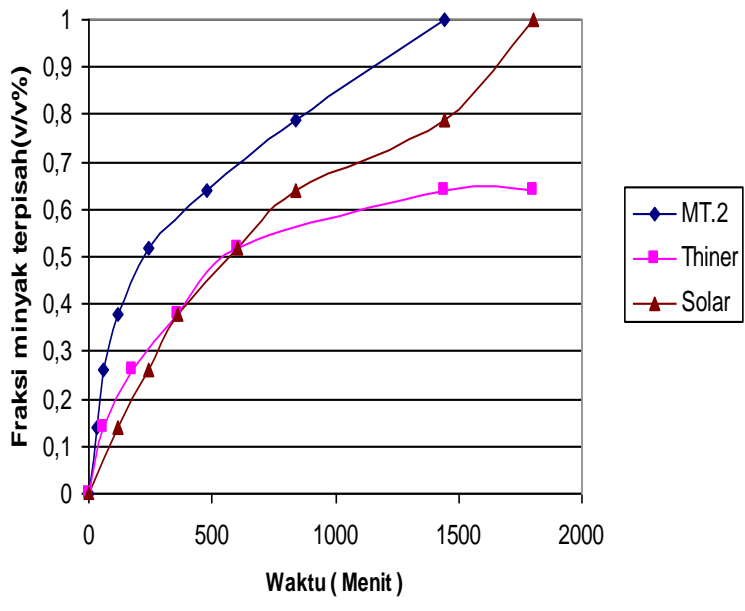

(b) $2 \mathrm{ppm}$
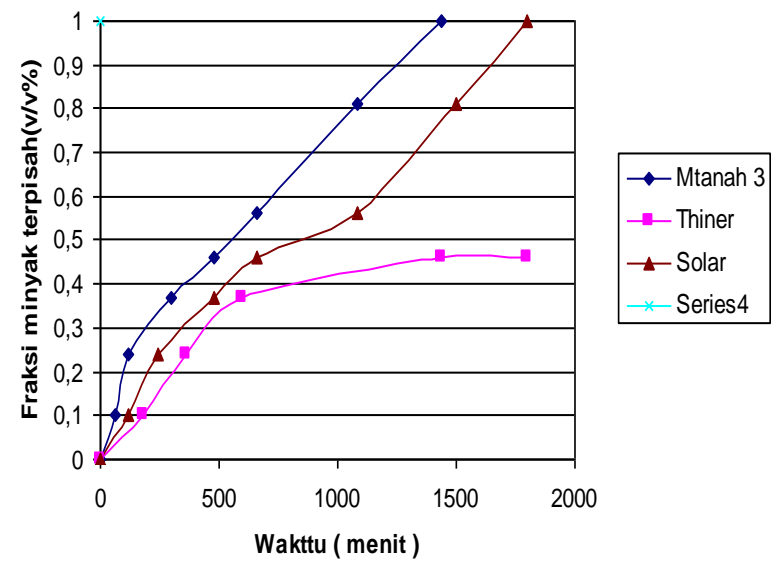

(c) 3 ppm

Gambar 1. Kestabilan emulsi dengan kadar EC berbeda pada lapisan minyak

Tabel 3. Jumlah nyamuk aedes aegypti strain Semarang yang mati dalam glas chamber

\begin{tabular}{ccccccc}
\hline \multirow{2}{*}{ Waktu (jam) } & $\begin{array}{c}\text { Jumlah Nyamuk } \\
\text { Aedes aegypti }\end{array}$ & \multicolumn{5}{c}{ Konsentrasi insektisida dg solvent thiner ( \% v/v) } \\
\cline { 3 - 6 } & $60^{*}$ & 0,75 & 0,5 & 0,25 & 0,125 & 0,0625 \\
\hline \multirow{2}{*}{$0^{\prime} 30^{\prime \prime}$} & & 0 & 0 & 0 & 0 & 0 \\
$1^{\prime} 00^{\prime \prime}$ & & 0 & 0 & 0 & 0 & 0 \\
$8^{\prime} 00^{\prime \prime}$ & & 1 & 1 & 1 & 0 & 0 \\
$15^{\prime} 00^{\prime \prime}$ & & 4 & 3 & 2 & 0 & 0 \\
$20^{\prime} 00^{\prime \prime}$ & & 7 & 6 & 6 & 0 & 0 \\
$24^{\prime} 00^{\prime \prime}$ & 20 & 20 & 20 & 18 & 9 & 2 \\
& \% kematian & 100 & 100 & 90 & 45 & 10 \\
\hline
\end{tabular}




\section{KESIMPULAN}

Emulsifier concentrat yang terbaik adalah pada percobaan dengan komposisi $20 \mathrm{gr}$ propoxure; $5 \mathrm{gr}$ malathion, $20 \mathrm{gr}$ agrisol; $15 \mathrm{gr}$ DBS, 55 gr Xyline; 2 gr IPA, 2 gr PG dan $1 \mathrm{gr}$ Toluen. Dengan emulsifier concentrat $30 \%$ atau 30 EC. Dari uji kestabilan antara minyak dan air didapat pelarut yang terbaik adalah thiner, dengan membentuk micro emulsi pada air dan CMC tercapai pada 0,42. thiner lebih baik dibandingkan solar dan minyak tanah. Dosis yang digunakan setelah dilakukan foging 0,025 -0,25\% $(\mathrm{v} / \mathrm{v})$, baik untuk telur nyamuk maupun jentik Aedes aegypti dengan prosentasi kemation 45$90 \%$

\section{DAFTAR PUSTAKA}

Anonymous, 2004. Pestisida dan Higiene Lingkungan. Laporan Tahunan Komisi Pestisida. Subdit Arbovirous, Direktorat Jenderal P3M - Departemen Kesehatan RI. 60 hal,

Binks. B.P. \& Whitby, C.P. 2003. Temperaturedependent stability of water-in-undecanol emulsions. Colloid and Surfaces $A$ : Physicochem. Eng. Aspects 224:241-249.

Dungan, S.R; Tai, B.H \& Gerhardt, N.I. 2003. Transport mechanisms in micellar sollubilization of alkanes in oil-in-water emulsion. Colloids and Surfaces $A$ : Physicochem. Eng. Aspects. 216:149 -166.

Edwards, D.A., Brenner, H., \& Wasan, D.T. 1991. Interfacial Transport Processes and Rheology. Butter-Heinemann, Boston M.A. 213 p.

Hendartini, 2003. Penelitian Pembuatan Formulasi Pestisida Bentuk Pekatan Yang Dapat
Diemulsikan. Balai Besar Penelitian dan Pengembangan Industri Kimia, Departemen Perindustrian dan Perdagangan. Jakarta. 23 hal.

Candra, A., 2010. Demam Berdarah Dengue: Epidemiologi, Patogenesis, dan Faktor Risiko Penularan. J. Penelitian Penyakit Tular Vektor. 2(2):110-119

Magdassi, S., Ben Moshe, M., Talmon., \& Danino, D. 2003. Colloid and Surfaces A : Physicochem. Eng. Aspects 212:1-7.

Opawale, Foyeke.O \& Burgess, Diane J. 1998. Influence of Interfacial Properties of Lipophilic Surfactant on Water-in-Oil Emulsion Stability. J. Colloid Interface Sci. 197:142-150.

Porter, M.R. 1994. Handbook Of Surfactant. $2^{\text {nd }}$ Ed. Blackie Academic \& Profesional. Madras. 324 p.

Sjoblom. A.J. 1996. Emulsion and Emulsion Stability. Marcel Dekker. New York. 234 p.

Steel, R.G.D \& Torrie, J.H. 1991. Principles and Procedurs of Statistics. McGraw-Hill Int. Book Cop. Tokyo. 630 p.

Sumingkrat. 1992. Kestabilan Emulsi Pestisida Bentuk Emulsifier Concentrate. Balai Besar Penelitian dan Pengembangan Industri Kimia, Departemen Perindustrian dan Perdagangan. Jakarta. 56 hal.

Timmermann, F. 2000. Food Emulsifier, Basic Theory to Practical Realities. J. Asia Pacific Food Industry. 12:1 -7

Wydro, P. \& Paluch, M. 2004. Surface properties od cationic-nonionic mixed surfactant systems. Colloid and Surfaces $A$ : Physicochem. Eng. Aspects 245:75 - 79. 